\title{
Walking Environment and Obesity: A Gender-Specific Association Study in Shanghai
}

\author{
Hei Gao ${ }^{1,2}$, Zike Xu ${ }^{3}$, Yu Chen ${ }^{1}$, Yutian Lu ${ }^{4}\left(\mathbb{D}\right.$ and Jian Lin ${ }^{5, *}$ \\ 1 The Architectural Design \& Research Institute of Zhejiang University Co., Ltd., Zhejiang University, \\ Hangzhou 310028, China; gh1@zuadr.com (H.G.); cyzuadr@126.com (Y.C.) \\ 2 Center for Balanced Architecture, Zijingang Campus, Zhejiang University, Hangzhou 310058, China \\ 3 College of Agriculture and Biotechnology, Zhejiang University, Hangzhou 310058, China; \\ 22016271@zju.edu.cn \\ 4 College of Computer Science and Technology, Zhejiang University, Hangzhou 310058, China; \\ yutianlu@zju.edu.cn \\ 5 Department of Urban and Regional Planning, College of Urban and Environmental Sciences, \\ Peking University, Beijing 100871, China \\ * Correspondence: linjianpku@163.com; Tel.: +86-010-6275-1176
}

check for updates

Citation: Gao, H.; Xu, Z.; Chen, Y.; Lu, Y.; Lin, J. Walking Environment and Obesity: A Gender-Specific Association Study in Shanghai. Int. J. Environ. Res. Public Health 2022, 19, 2056. https://doi.org/10.3390/ ijerph19042056

Academic Editor: Man Yuan

Received: 27 January 2022

Accepted: 10 February 2022

Published: 12 February 2022

Publisher's Note: MDPI stays neutral with regard to jurisdictional claims in published maps and institutional affiliations.

Copyright: (C) 2022 by the authors. Licensee MDPI, Basel, Switzerland. This article is an open access article distributed under the terms and conditions of the Creative Commons Attribution (CC BY) license (https:// creativecommons.org/licenses/by/ $4.0 /)$.

\begin{abstract}
Walking environment is commonly cited as an element that reduces the risk of obesity. Many literatures have shown that the impact of walking environment on the incidence rate of obesity may vary across gender, but few studies have conducted in-depth investigations. The present study aimed to provide empirical evidence for a cross-sectional association between the built community environment and the incidence of obesity among male and female residents. Thus, we collected height and weight level of 1355 residents and constructed seven walking environment indicators around 54 communities. Also, BMI was calculated and categorized to define overweight and obesity. We used generalized estimation equation to evaluate the gender-specific association between walking environment on obesity based on a diverse population sample. The study showed that female residents who lived in neighborhoods with higher road sky view index ( $p=0.033$; OR $=0.002$ [95\% $\mathrm{CI}=0.001-0.619])$ and increased intersection density $(p=0.009 ; \mathrm{OR}=0.979$ [95\% CI $=0.963-0.995])$ showed lower risk of increased BMI, but the advantage does not successfully radiate significant obesity consequences. In addition, the increased density of bus stops can also reduce the risk of obesity in women groups ( $p=0.035 ; \mathrm{OR}=0.910$ [95\% CI $=0.836-0.990]$ ). These findings suggest that women were more sensitive and were more likely to make different behavioral choices and physiological responses due to distinct walking environments. This provides useful evidence for future obesity prevention and urban planning.
\end{abstract}

Keywords: obesity; BMI index; walking environment; gender

\section{Introduction}

The consequences of obesity have been well documented [1-3]. Cumulative evidence indicates that obese individuals are at greater risk of some chronic diseases, especially type II diabetes [4,5], cardiovascular diseases [6], obstructive sleep apnea [7], and cancer [8]. Potential factors affecting obesity risk have been identified in literature [9-12]. In particular, walking environment $[13,14]$ has received considerable attention due to changeability leading to health weight. Different walking environments affect the incidence of obesity by indirectly influencing residents' physical exercise, as well as walking behaviors, a notion widely recognized by academia [15].

However, limited information is known about whether the walking environment affects the risk of obesity indiscriminately in different social groups. Understanding which populations might be most vulnerable to the obesogenic environment is of great significance for improving urban built environments and targeting obesity prevention 
interventions. Taking gender as an example, men and women have certain disparities in the scope, frequency, and perceived experience of the walking environment [16-18]; thus, the behavioral choices they make and the opportunities and risks they face in the same construction might vary greatly $[19,20]$. Therefore, men and women are often exposed to obesity-driven risk factors to varying degrees, thereby forming different biological responses (Figure 1). Although the mechanism of the walking environment's influence on obesity is relatively clear, the interaction among gender differences, walking environment, and incidence of obesity has been rarely investigated. Hence, this article will focus on the effect of gender differences on the obesity risk of residents affected by the walking environment and explore different underlying mechanisms.

\section{Built environment}

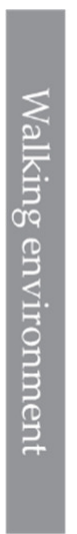

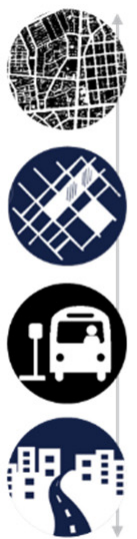

Biological Response

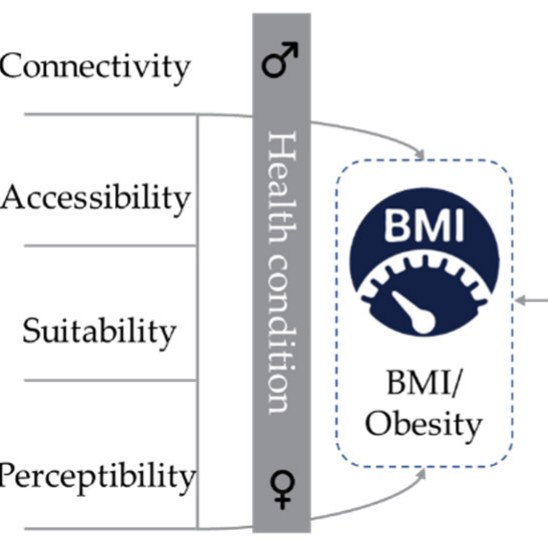

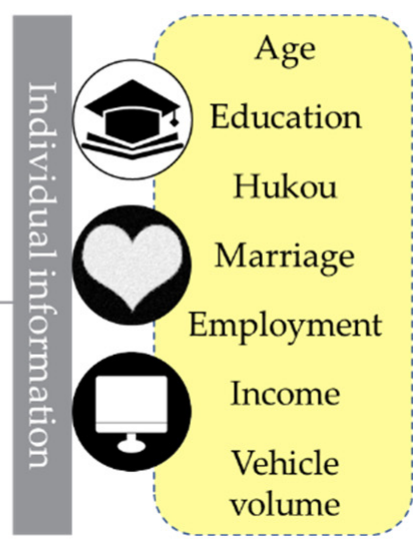

\section{Individual characteristics}

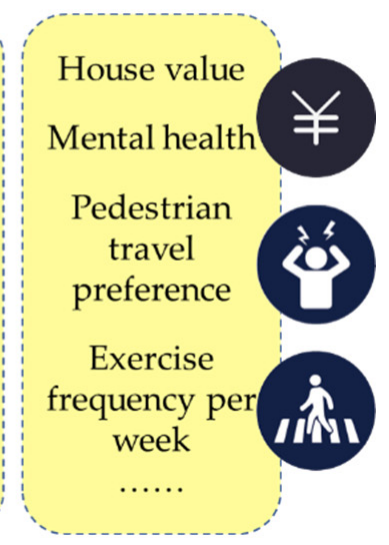

Figure 1. Research framework.

A great quantity of literature mentions that women are much less likely to use walking environments and public spaces than men [16], both in terms of time and space. Women's increased concerns about safety in their daily lives also make their use of open spaces such as streets less frequent than men's [21,22]. Such unfair access to public space resources grants men greater discourse power in urban planning. Urban planning $[23,24]$ that caters to males also grants men greater activity space and frequency of use in the built environment than women, further consolidating their dominant position. Thus, we can infer that: The impact of walking environment on BMI index and obesity risk in men should be more significant than that in women. Women are less affected by the walking environment due to their lower use of public space; men, on the other hand, spend more time in open spaces and experience more of the walking environment around the neighborhood, which also has a deeper impact on their behavioral choices.

Since men and women are often exposed to obesity-driven risk factors to varying degrees, the present study will focus on the gender differences in the obesity risk of residents affected by the built environment and explore the different mechanisms of its impact on obesity. We constructed a collection of walking environmental indicators by information and communication technology. Then, we prepared a resident health sampling questionnaire to assess the health status and individual characteristics of interviewees. Finally, two sets of models were established using the generalized estimation equation. According to the total sample, male sample, and female sample, the impact mechanism of the walking environment on the risk of obesity of residents was explored. Similarities and differences in the obtained results were also analyzed and discussed. Suggestions are put forward for local urban planning. 


\section{Materials and Methods}

\subsection{Study Sample}

"Daily Activities and Travel Survey of Shanghai Residents" was conducted in 2017 by using the method of cluster sampling survey from residents living in 54 communities from eight administrative regions of Shanghai (including Jiading District, Fengxian District, Baoshan District, Songjiang District, Pudong New Area, Jinshan District, Minhang District, and Qingpu District) (Figure 2). We have strictly defined the interviewees: (1) the parents' and children's (if any) BMI should not be greater than 30 to avoid the genetic impact obesity; (2) the respondents should live in the current residential area for more than 5 years to fully reflect the impact of the built environment; (3) the average respondent should spend less than $6 \mathrm{~h}$ a day sitting between 9:00-17:00 daily; and (4) The respondents are neither heavy smokers nor alcoholics. The missing data were omitted from the original participants $(n=1479)$. Finally, 718 men and 637 women $(n=1355)$ were selected to constitute the analysis sample (91.6\% of the original sample).
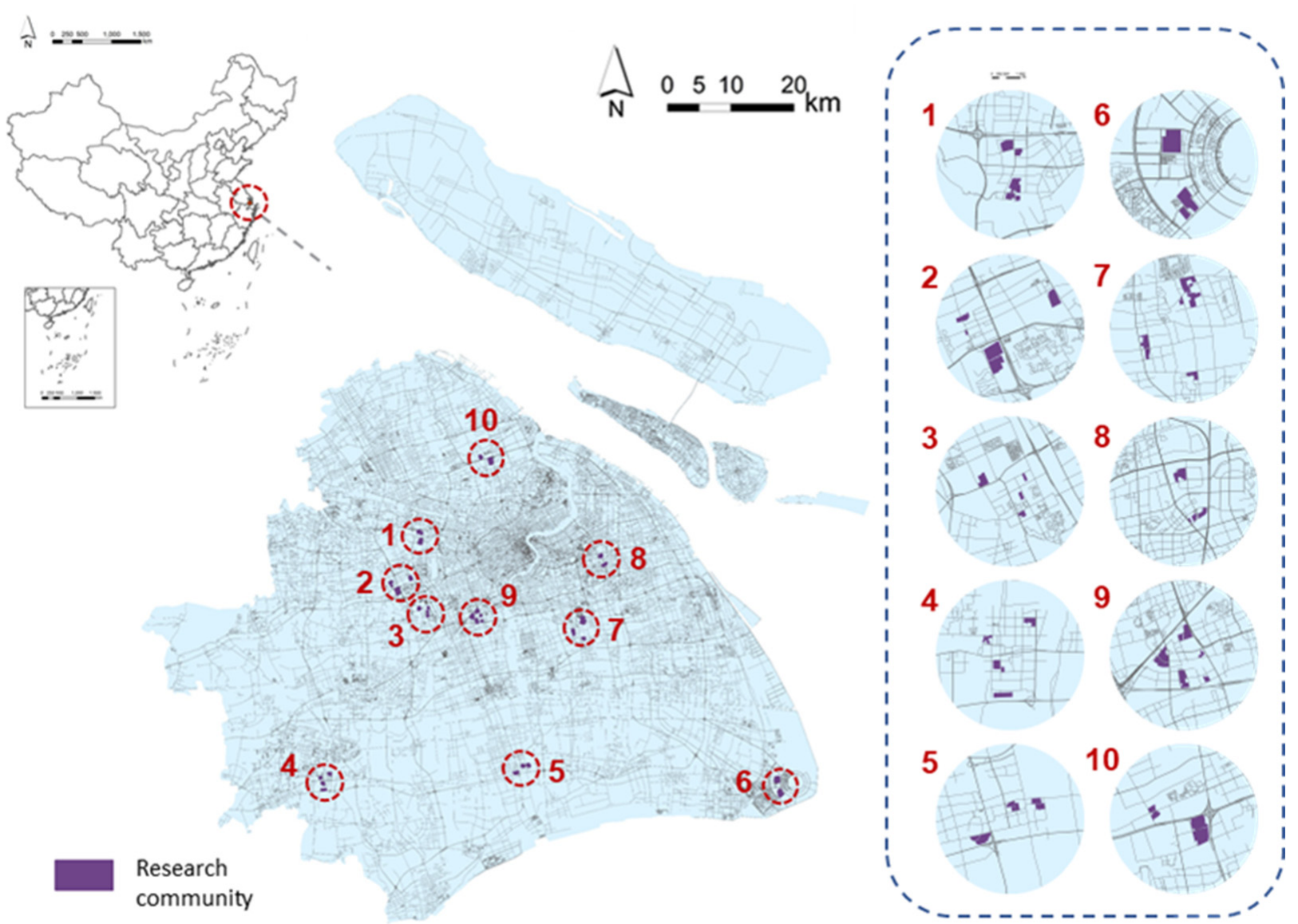

Figure 2. Location of study area.

Scholars have argued that Shanghai should be an ideal example to examine typical global issues. Located in the Yangtze River Delta, Shanghai is one of the most developed megacities in China, with an area of $6340 \mathrm{~km}^{2}$ and a population of 24.24 million people. Having experienced amazing socio-economic development and large-scale urban expansion in the past few decades, Shanghai has profoundly recognized the significance of people's health during the development process. To this end, the local government has initialized a new healthy city plan, which emphasizes the optimization of the built environment and equal enjoy rights. In terms of the walking environment, residents should make full use of the park, forest belt, roof, and other green spaces along the river; and take $15 \mathrm{~min}$ of walking as the scale of community living space, closely around the clothing, food, 
housing, and transportation, forming a life circle for community residents. Moreover, the walking environment of Shanghai blocks may vary greatly due to historical legacy (the concession area became a state that was not administered by the local government), thereby providing a typical case for studying the walking environment. In order to eliminate the influence of food environment confounding factors, we measure the food environment of the sampled communities (Supplementary description S1). After the statistics of the food accessibility index of each community, we found that the food accessibility index of different communities was about 2.89 , with a small standard deviation of 1.34 . Therefore, there is no significant difference in the food environment exposure between samples.

\subsection{Key Study Variables}

\subsubsection{Outcome Variables}

Resident weight status. Residents were assessed by trained technicians at the collection centres as the participants wore light clothes and no shoes. Anthropometrics' body weight and height were measured twice at each interview, using a digital scale recording to the nearest $0.1 \mathrm{~kg}$ and the Seca 202 device recording to the nearest $0.1 \mathrm{~cm}$, respectively. The two height \& weight measurements were averaged if the difference between them is within the accidental error. Otherwise, the measurement nearer to the median weight/height for that age was retained. The measured weight and height were used to calculate BMI $\left(\mathrm{kg} / \mathrm{m}^{2}\right)$ for each resident. We also define another outcome variable named "Obesity index" as an ordered Logistic function. In this variable, overweight was defined as BMI $\geq 25 \mathrm{~kg} / \mathrm{cm}^{2}$, and obesity was supposed to BMI $\geq 30 \mathrm{~kg} / \mathrm{cm}^{2}$. In our sample, $83.6 \%$ of residents had a BMI of less than $25 \mathrm{~kg} / \mathrm{m}^{2}$, showing a relatively healthy state. $16.4 \%$ of residents were considered an alarming health risk, i.e., their BMI was greater than or equal to $25 \mathrm{~kg} / \mathrm{m}^{2}$. Among this group, $1.3 \%$ of residents were already obese, with a BMI of $30 \mathrm{~kg} / \mathrm{m}^{2}$ or higher.

\subsubsection{Exposure Variables: Walking Environment}

Our studies followed various frameworks, such as 5C [25], 7C [26], 3D [27], 5D [28], SPCES [29], IMI [30], PEDS [31], and SP [32], to guide the selection and structuring of street walkability indicators. These frameworks have basically the same meaning, but different ways of expressing it. We first collected the definitions and expression of all the components in the framework and then used natural language processing for word frequency analysis. Words with frequency higher than the $30 \%$ quantile threshold are retained. Experts from related industries (e.g., Urban Planning Bureau, Traffic Management Bureau, etc.) were invited to participate in the evaluation process. Experts rated each item by judging the measurability, discernibility, verifiability and scale suitability of each item on a scale of 1 (very unsuitable) to 5 (very suitable). Then calculate the average score of each item by assigning equal weights to all criteria and experts, and items were discarded when one or more experts assigned very low values to them or indicated that they were grossly inappropriate. We further invited experts to judge the classification and classified the preserved items as the main component.

After several rounds of feedback, a consensus on the classification was reached, finally forming the walking environment evaluation index system (Table S1). More specifically, the framework consisted of four fundamental components (including connectivity [33,34], accessibility [35,36], suitability [26,37], and perceptibility [38]), as well as seven more detailed indexes that were selected from 12 indexes after the collinearity test, containing road intersection density, land use mix index, number of bus stops within $500 \mathrm{~m}$ of the community border, Ratio Vegetation Index (RVI), community green space rate, road green view index, and road sky view index. Among them, RVI is a sensitive indicator parameter for green plants for detecting and estimating plant biomass. All of these indexes were constructed at a community level and were the finest geographic unit at which walking environments have been associated with residents' outdoor physical activity. In order to describe the walking environment more accurately, five national geographic datasets available in 2017 were used across Shanghai in a GIS environment, including the second 
national land survey data, remote sensing image data, POI datasets, road network datasets, and street view datasets.

\subsubsection{Covariates}

Socio-demographic covariates comprised gender, age, education, hukou, marriage, employment, income, house values, housing property, exercise frequency per week, pedestrian travel preference, and vehicle volume. Among them, income (including the sum of wages, pensions, subsistence allowances, other non-wage income, etc.), house value, vehicle volume, along with exercise frequency per week, were assessed from self-reported data. Residents' marital status was defined as married, unmarried, divorced, and widowed. Self-reported information on highest degree obtained was used to classify participants into six education categories: primary school and below, junior high school, senior school (including polytechnic school and vocational high school), college, university, bachelor's or higher. Employment status included full-time employment, half-time employment, temporary employment, school students, retired at home, unemployed, and others. Respondents reported their Hukou as falling into one of four categories: Shanghai non-agricultural household hukou, Shanghai agricultural household hukou, nonlocal non-agricultural household hukou, and non-local agricultural household hukou. Housing property was recorded into two categories: head of household and non-head of household. Similarly, pedestrian travel preference was also grouped into five categories due to questionnaire answers, including very dislike, relatively dislike, normal, relatively like, and very like.

\subsection{Statistical Analyses}

In this study, we conducted the LSD Multiple Test on various indexes of walking environments. Furthermore, chi-square analysis was used to test differences in individual characteristics of male and female residents, while the heterogeneity test was used to examine the differences between walking environment of men and women. After the collinearity test, no evidence of multicollinearity (VIF $<10)$ was found. The statistical significance was set to $\alpha<0.05$.

We identified important gender differences in the relationship between obesity (BMI) and walking environment by using generalized estimation equation (GEE) with the clustering of sample selection at the community level. This study evaluated two models in total. These two models demonstrated the impact mechanism of walking environment on weight gain or obesity, respectively, with BMI/Obesity index as the dependent variables and various indicators measuring walking environment as the independent variables. We adjusted for covariates (age, gender, marital status, education, Hukou, employment, income, house value, housing property, exercise frequency per week, pedestrian travel preference, and vehicle volume) that could be potential confounders or predictors of obesity. Among them, exercise frequency per week and the amount of vehicle volume were included in the sensitivity analysis as additional factors. Then, the OR value and its $95 \%$ confidence interval were calculated while exploring its significance. All operations are performed in SPSS 25.0 and Stata 12.0.

Each model evaluated three samples: Sample 1 included all participants, while only male residents were included in Sample 2 and only female residents were included in Sample 3. The model formula of the generalized estimation equation is as follows:

$$
\begin{gathered}
\mathrm{E}\left(Y_{i j}\right)=\mu_{i j} \\
\mathrm{~g}\left(\mu_{i j}\right)=\beta_{0}+\beta_{\text {walk }} X_{\text {walkij }}
\end{gathered}
$$

where $\mathrm{g}$ is the connection function, and $\beta_{0}$ and $\beta_{\text {walk }}$ are parameter vectors to be estimated by the model; $Y_{i j}$ is the BMI index or Obesity index measured by the $j$-th individual in the $i$-th community; and $X_{w a l k i j}$ is the walking environment index group corresponding to $Y_{i j}$.

$$
X_{i j w a l k}=\left(C_{i j}, A_{i j}, S_{i j}, P_{i j}\right)
$$




\section{Results}

\subsection{Descriptive Statistics}

The sociodemographic and health status of the samples are listed in Table 1. Males and females show significant differences among BMI index $(p<0.001)$, education level $(p<0.001)$, marital status $(p<0.001)$, employment conditions $(p<0.001)$, and exercise frequency per week $(p=0.025)$. The BMI index of male samples is significantly greater than that of females, which are 22.97 and 21.44, respectively. In terms of employment conditions, the ratio of full-time employment of male residents is significantly higher, and the number of retired and unemployed individuals is relatively small. The proportion of women with higher education was significantly lower, especially up to $5.97 \%$ of the females have only primary school education or below. In the aspect of marital status, more women are married and widowed than men. Additionally, male and female residents exercised 3.16 times and 2.91 times a week, indicating that males are significantly higher than females. Although no significant differences in other individual characteristics were found, the average age of the female sample is about 1 year older than that of the male, and the overall income level of the male is slightly higher; compared with male residents, females are often more willing to travel on foot.

Table 1. Individual characteristics and differences between male and female participants $(n=1355)$.

\begin{tabular}{|c|c|c|c|c|}
\hline Characteristic & Total $(n=1355)$ & Male $(n=718)$ & Female $(n=637)$ & $p^{\mathrm{a}}$ \\
\hline $\mathrm{BMI} / \mathrm{kg} / \mathrm{m}^{2}$ (mean (SD)) & $22.25(2.92)$ & $22.97(2.81)$ & $21.44(2.84)$ & $<0.001^{b}$ \\
\hline Age/year (mean $(\mathrm{SD}))$ & $38.75(11.42)$ & $38.02(11.51)$ & $39.58(11.28)$ & 0.081 \\
\hline \multicolumn{5}{|l|}{ Education $(n(\%))$} \\
\hline Primary school and below & $51(3.76 \%)$ & $13(1.81 \%)$ & $38(5.97 \%)$ & \multirow{6}{*}{$<0.001$} \\
\hline Junior high school & $258(19.04 \%)$ & $116(16.16 \%)$ & $142(22.29 \%)$ & \\
\hline $\begin{array}{l}\text { Senior school (including polytechnic school and } \\
\text { vocational high school) }\end{array}$ & $325(23.99 \%)$ & $189(26.32 \%)$ & $136(21.35 \%)$ & \\
\hline College & $273(20.15 \%)$ & $148(20.61 \%)$ & $125(19.62 \%)$ & \\
\hline University & $382(28.19 \%)$ & $214(29.81 \%)$ & $168(26.37 \%)$ & \\
\hline Bachelor's or higher & $66(4.87 \%)$ & $38(5.29 \%)$ & $28(4.40 \%)$ & \\
\hline \multicolumn{5}{|l|}{ Hukou $(n(\%))$} \\
\hline Shanghai non-agricultural household hukou & $650(47.97 \%)$ & $353(49.16 \%)$ & $297(46.62 \%)$ & \multirow{4}{*}{0.097} \\
\hline Shanghai agricultural household hukou & $62(4.58 \%)$ & $24(3.34 \%)$ & $38(5.97 \%)$ & \\
\hline Non local non-agricultural household hukou & $375(27.68 \%)$ & $193(26.88 \%)$ & $182(28.57 \%)$ & \\
\hline Non local agricultural household hukou & $268(19.78 \%)$ & $148(20.61 \%)$ & $120(18.84 \%)$ & \\
\hline \multicolumn{5}{|l|}{ Marriage $(n(\%))$} \\
\hline Married & $1077(79.48 \%)$ & $537(74.79 \%)$ & $540(84.77 \%)$ & \multirow{4}{*}{$<0.001$} \\
\hline Unmarried & $262(19.34 \%)$ & $172(23.96 \%)$ & $90(14.13 \%)$ & \\
\hline Divorced & $11(0.81 \%)$ & $8(1.11 \%)$ & $3(0.47 \%)$ & \\
\hline Widowed & $5(0.37 \%)$ & $1(0.14 \%)$ & $4(0.63 \%)$ & \\
\hline \multicolumn{5}{|l|}{ Employment $(n(\%))$} \\
\hline Full-time employment & $980(72.32 \%)$ & $573(79.81 \%)$ & $407(63.89 \%)$ & \multirow{7}{*}{$<0.001$} \\
\hline Half-time employment & $27(1.99 \%)$ & $13(1.81 \%)$ & $14(2.20 \%)$ & \\
\hline Temporary employment & $16(1.18 \%)$ & $9(1.25 \%)$ & $7(1.10 \%)$ & \\
\hline School students & $48(3.54 \%)$ & $32(4.46 \%)$ & $16(2.51 \%)$ & \\
\hline Retired at home & $141(10.41 \%)$ & $45(6.27 \%)$ & $96(15.07 \%)$ & \\
\hline Unemployed & $138(10.18 \%)$ & $42(5.85 \%)$ & $96(15.07 \%)$ & \\
\hline Other & $5(0.37 \%)$ & $4(0.56 \%)$ & $1(0.16 \%)$ & \\
\hline \multicolumn{5}{|l|}{ Housing property $(n(\%))$} \\
\hline Head of household & $869(64.13 \%)$ & $436(60.72 \%)$ & $438(68.76 \%)$ & \multirow{2}{*}{0.650} \\
\hline Non-head of household & $486(35.87 \%)$ & $282(39.28 \%)$ & $199(31.24 \%)$ & \\
\hline
\end{tabular}


Table 1. Cont.

\begin{tabular}{|c|c|c|c|c|}
\hline Characteristic & Total $(n=1355)$ & Male $(n=718)$ & Female $(n=637)$ & $p^{\mathrm{a}}$ \\
\hline \multicolumn{5}{|l|}{ Pedestrian travel preference $(n(\%))$} \\
\hline Very dislike & $25(1.85 \%)$ & $12(1.67 \%)$ & $13(2.04 \%)$ & \multirow{5}{*}{0.118} \\
\hline Relatively dislike & $135(9.96 \%)$ & $75(10.45 \%)$ & $60(9.42 \%)$ & \\
\hline Normal & $529(39.04 \%)$ & $299(41.64 \%)$ & $230(36.11 \%)$ & \\
\hline Relatively like & $516(38.08 \%)$ & $263(36.63 \%)$ & $253(39.72 \%)$ & \\
\hline Very like & $150(11.07 \%)$ & $69(9.61 \%)$ & $81(12.72 \%)$ & \\
\hline House value/RMB (mean (SD)) & $\begin{array}{c}3,105,758.18 \\
(1,825,849.11)\end{array}$ & $\begin{array}{c}3,062,767.56 \\
(1,908,874.76)\end{array}$ & $\begin{array}{c}3,154,215.43 \\
(1,727,703.53)\end{array}$ & 0.589 \\
\hline \multicolumn{5}{|l|}{ Vehicle volume (mean (SD)) } \\
\hline Number of cars & $0.65(0.61)$ & $0.65(0.61)$ & $0.64(0.61)$ & 0.278 \\
\hline $\begin{array}{l}\text { Number of electric vehicles /mopeds } \\
\text { /motorcycles }\end{array}$ & $0.61(0.68)$ & $0.64(0.69)$ & $0.59(0.66)$ & 0.393 \\
\hline Number of bicycles & $0.44(0.65)$ & $0.43(0.68)$ & $0.45(0.62)$ & 0.813 \\
\hline Exercise frequency per week/Times (mean (SD)) & $3.04(2.99)$ & $3.16(3.04)$ & $2.91(2.93)$ & 0.025 \\
\hline Income/RMB (mean (SD)) & $\begin{array}{c}15,727.07 \\
(21,847.11)\end{array}$ & $15,892.76(20,947.84)$ & $15,540.31(22,833.46)$ & 0.232 \\
\hline
\end{tabular}

${ }^{a}$ significant result expressed as chi-square test. ${ }^{\mathrm{b}}$ bold text indicates statistical significance $(p<0.05)$.

The heterogeneity of the walking environment exposed by the participants of different genders are listed in Figure 3. The results showed that even though men and women experience a certain degree of differences in walking environment, there is no significant heterogeneity between them. This is consistent with our guess; men and women are usually randomly distributed in distinct communities.

Total

Walking environment

Road green view index

Road sky view index

RVI index

Number of bus stops

Community green space rate

Land use entropy

Road intersection density
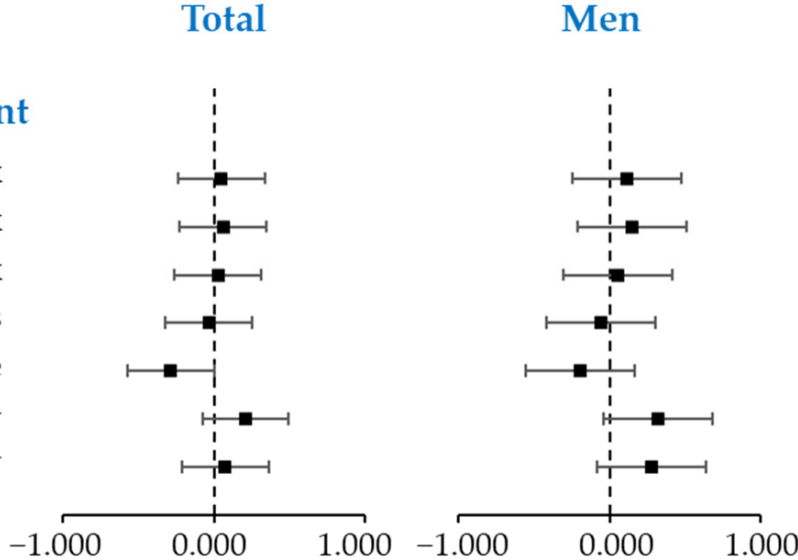

Men

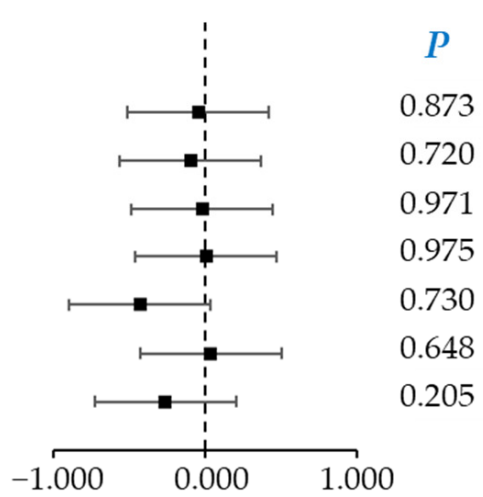

Figure 3. The heterogeneity of the built environment between men and women.

We further analyzed the discrepancies between each level of walking environment (Figure 4). The quartiles are used to divide the walking environment indexes into four levels: low, lower, higher, and high. Only the RVI index of the lower and higher levels is significant $(p=0.043)$, indicating that a large difference exits in the risk of obesity among residents of these two levels. Besides, more levels in the road sky view index, such as low level and higher level $(p=0.030)$, lower level and higher level $(p=0.001)$, lower level and high level ( $p=0.050)$ have significant differences, showing that different grades of streets blue space have a greater impact on the shape of the residents. 


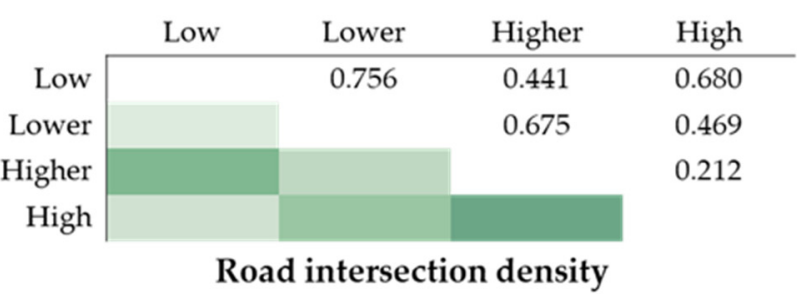

\begin{tabular}{|c|c|c|c|c|}
\hline & Low & Lower & Higher & High \\
\hline Low & & 0.312 & 0.711 & 0.356 \\
\hline Lower & & & 0.506 & 0.043 \\
\hline Higher & & & & 0.179 \\
\hline High & & & & \\
\hline
\end{tabular}
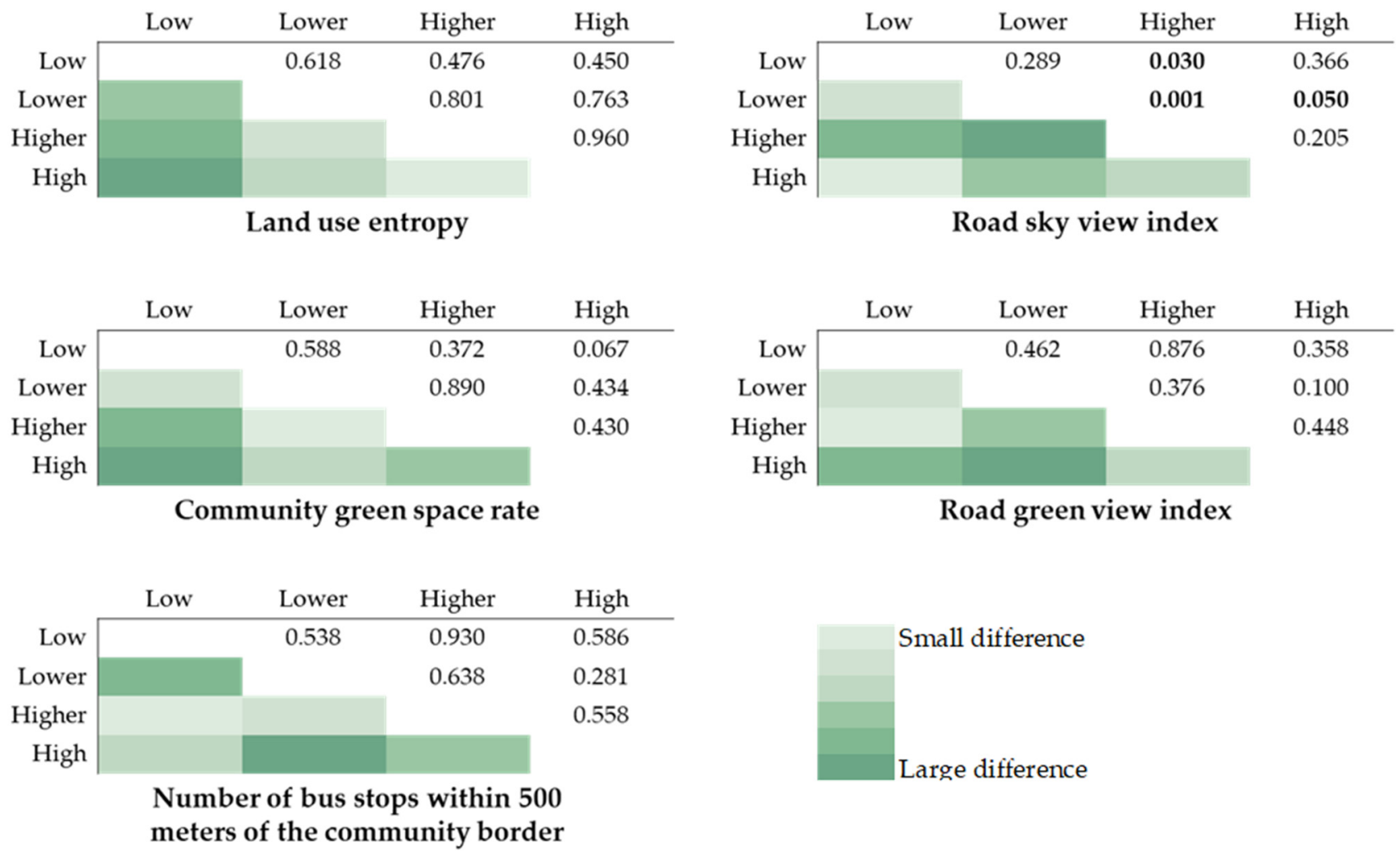

Figure 4. Multiple tests between each level in the built environment.

\subsection{Gender Differences in Weight Gain}

In Model 1 with the BMI index as the dependent variable, for the total sample of $n=1355$, the cross-sectional correlations between all indicators of walking environment and BMI index are relatively small and not statistically significant (Table 2). This might be due to sample selections, because the mechanism of the impact of walking environment on residents' weight gain is diverse, and men and women often show different reactions in different walking environments. Therefore, we divided the total sample into male sample and female sample and analyzed the different results between them.

The sample of male residents $(n=718)$ shows that the association between all walking environment indicators and obesity remains non-significant; while the female sample $(n=637)$ shows that the road intersections density ( $p=0.009 ; \mathrm{OR}=0.979[95 \% \mathrm{CI}=0.963-0.995])$ and road sky view index $(p=0.033 ; \mathrm{OR}=0.002$ [95\% CI $=0.001-0.619])$ are significant, indicating that a higher road network topology and spacious road sky view have a positive effect on the reduction of the BMI index of female residents, which is evidently different from the male sample and the total sample. Surprisingly, a higher RVI index was significantly associated with an increase in BMI among female residents ( $p=0.050$; OR $=1.641$ [95\% $C I=1.001-2.692])$. This might be due to a better vegetation index often representing a more canopied and insecure environment $[39,40]$. Also, women are more concerned about security $[41,42]$, so they often feel more anxious and fearful in such spaces. 
Table 2. Generalized linear estimation equations testing for the increased BMI among residents based on walking environment.

\begin{tabular}{|c|c|c|c|c|c|c|}
\hline \multirow{2}{*}{ Model 1} & \multicolumn{2}{|c|}{ Total Sample } & \multicolumn{2}{|c|}{ Male Sample } & \multicolumn{2}{|c|}{ Female Sample } \\
\hline & $\begin{array}{c}p- \\
\text { Value }\end{array}$ & OR $(95 \% \mathrm{CI})$ & $\begin{array}{c}p- \\
\text { Value }\end{array}$ & OR $(95 \% \mathrm{CI})$ & $\begin{array}{c}p- \\
\text { Value }\end{array}$ & OR $(95 \% \mathrm{CI})$ \\
\hline \multicolumn{7}{|l|}{ Walking environment } \\
\hline Road intersection density & 0.227 & $0.994(0.985,1.004)$ & 0.104 & $1.008(0.998,1.019)$ & 0.009 & $0.979(0.963,0.995)$ \\
\hline Land use entropy & 0.559 & $1.241(0.602,2.558)$ & 0.633 & $1.210(0.553,2.647)$ & 0.455 & $1.601(0.466,5.504)$ \\
\hline Community green space rate & 0.375 & $0.988(0.962,1.015)$ & 0.277 & $0.983(0.952,1.014)$ & 0.838 & $0.996(0.955,1.038)$ \\
\hline $\begin{array}{l}\text { Number of bus stops within } \\
500 \text { m of the community border }\end{array}$ & 0.490 & $1.014(0.975,1.055)$ & 0.601 & $0.986(0.936,1.039)$ & 0.305 & $1.034(0.970,1.101)$ \\
\hline RVI index & 0.099 & $1.368(0.943,1.984)$ & 0.586 & $1.140(0.711,1.830)$ & 0.050 & $1.641(1.001,2.692)$ \\
\hline Road sky view index & 0.079 & $0.031(0.001,1.487)$ & 0.638 & $0.328(0.003,34.241)$ & 0.033 & $0.002(0.001,0.619)$ \\
\hline Road green view index & 0.358 & $0.213(0.008,5.761)$ & 0.344 & $4.660(0.192,112.86)$ & 0.059 & $0.012(0.001,1.176)$ \\
\hline \multicolumn{7}{|l|}{ Individual characteristics } \\
\hline \multicolumn{7}{|l|}{ Gender (Ref: Female) } \\
\hline Male & 0.000 & $5.352(3.866,7.410)$ & I & l & / & / \\
\hline Education & \multicolumn{6}{|c|}{ No significant effect shown, see Table S2 for details } \\
\hline Hukou & \multicolumn{6}{|c|}{ No significant effect shown, see Table S2 for details } \\
\hline Marriage & \multirow{2}{*}{\multicolumn{6}{|c|}{ No significant effect shown, see Table S2 for details }} \\
\hline Employment (Ref: Other) & & & & & & \\
\hline Full-time employment & 0.154 & $0.294(0.055,1.580)$ & 0.094 & $0.193(0.028,1.322)$ & 0.122 & $0.441(0.156,1.244)$ \\
\hline Half-time employment & 0.709 & $0.675(0.085,5.329)$ & 0.354 & $0.221(0.009,5.379)$ & 0.651 & $1.448(0.291,7.197)$ \\
\hline Temporary employment & 0.209 & $0.306(0.048,1.941)$ & 0.318 & $0.308(0.030,3.117)$ & 0.112 & $0.262(0.050,1.370)$ \\
\hline School students & 0.791 & $0.773(0.116,5.170)$ & 0.812 & $0.760(0.080,7.235)$ & 0.321 & $0.527(0.148,1.871)$ \\
\hline Retired at home & 0.027 & $0.165(0.034,0.812)$ & 0.006 & $0.068(0.010,0.471)$ & 0.038 & $0.276(0.082,0.928)$ \\
\hline Unemployed & 0.231 & $0.339(0.058,1.988)$ & 0.136 & $0.207(0.026,1.641)$ & 0.259 & $0.503(0.152,1.660)$ \\
\hline Housing property & \multicolumn{6}{|c|}{ No significant effect shown, see Table S2 for details } \\
\hline Pedestrian travel preference & \multicolumn{6}{|c|}{ No significant effect shown, see Table S2 for details } \\
\hline Age & 0.000 & $1.061(1.040,1.083)$ & 0.000 & $1.060(1.031,1.090)$ & 0.001 & $1.065(1.038,1.093)$ \\
\hline House value & 0.668 & $1.000(1.000,1.000)$ & 0.704 & $1.000(1.000,1.000)$ & 0.148 & $1.000(1.000,1.000)$ \\
\hline Number of cars & 0.616 & $0.936(0.722,1.212)$ & 0.871 & $0.973(0.699,1.355)$ & 0.877 & $0.970(0.658,1.429)$ \\
\hline $\begin{array}{l}\text { Number of electric vehicles } \\
\text { /mopeds / motorcycles }\end{array}$ & 0.280 & $0.881(0.699,1.109)$ & 0.340 & $0.856(0.623,1.177)$ & 0.827 & $0.956(0.639,1.430)$ \\
\hline Number of bicycles & 0.224 & $1.143(0.922,1.417)$ & 0.213 & $1.201(0.901,1.601)$ & 0.726 & $1.057(0.776,1.439)$ \\
\hline Exercise frequency per week & 0.381 & $1.024(0.972,1.078)$ & 0.215 & $1.043(0.976,1.116)$ & 0.856 & $0.991(0.904,1.087)$ \\
\hline Income & 0.044 & $0.958(0.800,0.999)$ & 0.842 & $0.977(0.960,1.023)$ & 0.000 & $0.920(0.902,0.980)$ \\
\hline
\end{tabular}

Dependent variable: BMI index; Bold text indicates statistical significance $(p<0.05)$.

After considering individual characteristics, we can see that gender differences have a significant effect on the risk of weight gain in the total sample $(p=0.000 ; \mathrm{OR}=5.352[95 \%$ $\mathrm{CI}=3.866-7.410]$ ), which is the basis to further explore the gender differences in the impact of built environment on obesity. In addition, the influence of age difference on weight gain is significant in all samples. Compared to young people, the elderly are more likely to be overweight. However, retired residents show a significant relationship with weight gain, indicating that they are less at risk of weight gain. Low resident income is also one of the significant risk factors for BMI increase, especially for female samples $(p=0.000)$.

\subsection{Gender Differences in Obesity}

In Model 2 with the "Obesity index" as the dependent variable (Table 3), as far as walking environment, all the indicators still do not show a significant statistical relationship with the risk of obesity for the total and the male samples, and yet in the female sample, number of bus stops within $500 \mathrm{~m}$ of the community border turns significant, showing that with a number of bus stops within $500 \mathrm{~m}$ of the community border increasing, the likelihood of residents being obese is reduced to $91.0 \%(p=0.035$; OR $=0.910$ [95\% CI $=0.836-0.990])$. 
This result indicates that improving the accessibility of bus stops has a positive significance for reducing the risk of obesity in women.

Table 3. Generalized linear estimation equations testing for the risk of obesity among residents based on walking environment.

\begin{tabular}{|c|c|c|c|c|c|c|}
\hline \multirow{2}{*}{ Model 2} & \multicolumn{2}{|c|}{ Total Sample } & \multicolumn{2}{|r|}{ Male Sample } & \multicolumn{2}{|c|}{ Female Sample } \\
\hline & $\begin{array}{c}p- \\
\text { Value }\end{array}$ & OR $(95 \% \mathrm{CI})$ & $\begin{array}{c}p- \\
\text { Value }\end{array}$ & OR $(95 \% \mathrm{CI})$ & $\begin{array}{c}p- \\
\text { Value }\end{array}$ & OR $(95 \%$ CI $)$ \\
\hline \multicolumn{7}{|l|}{ Walking environment } \\
\hline Road intersection density & 0.998 & $0.999(0.991,1.009)$ & 0.058 & $1.011(1.000,1.022)$ & 0.066 & $0.974(0.946,1.002)$ \\
\hline Land use entropy & 0.940 & $1.025(0.534,1.971)$ & 0.417 & $1.332(0.666,2.663)$ & 0.582 & $0.714(0.215,2.372)$ \\
\hline $\begin{array}{l}\text { Community green space } \\
\text { rate }\end{array}$ & 0.548 & $1.009(0.979,1.040)$ & 0.527 & $1.012(0.974,1.052)$ & 0.738 & $1.007(0.966,1.051)$ \\
\hline $\begin{array}{l}\text { Number of bus stops } \\
\text { within } 500 \mathrm{~m} \text { of the } \\
\text { community border }\end{array}$ & 0.713 & $1.009(0.964,1.055)$ & 0.237 & $0.966(0.913,1.023)$ & 0.035 & $0.910(0.836,0.990)$ \\
\hline RVI index & 0.264 & $1.307(0.817,2.090)$ & 0.555 & $1.169(0.697,1.959)$ & 0.568 & $1.468(0.393,5.488)$ \\
\hline Road sky view index & 0.387 & $0.147(0.002,11.339)$ & 0.455 & $0.150(0.001,21.657)$ & 0.418 & $0.021(0.001,234.921)$ \\
\hline Road green view index & 0.846 & $1.457(0.033,64.454)$ & 0.043 & $54.011(1.132,2576.444)$ & 0.123 & $0.007(0.002,3.924)$ \\
\hline \multicolumn{7}{|l|}{ Individual characteristics } \\
\hline \multicolumn{7}{|l|}{ Gender (Ref: Female) } \\
\hline Male & 0.000 & $2.799(1.849,4.237)$ & l & l & / & / \\
\hline Education & \multicolumn{6}{|c|}{ No significant effect shown, see Table S3 for details } \\
\hline Hukou & \multirow{2}{*}{\multicolumn{6}{|c|}{ No significant effect shown, see Table S3 for details }} \\
\hline Marriage (Ref: Widowed) & & & & & & \\
\hline Married & 0.163 & $0.293(0.052,1.646)$ & I & I & 0.132 & $0.123(0.008,1.877)$ \\
\hline Unmarried & 0.008 & $0.091(0.016,0.531)$ & l & I & 0.016 & $0.022(0.001,0.485)$ \\
\hline Divorced & 0.133 & $0.140(0.011,1.814)$ & l & I & 0.143 & $0.189(0.028,1.856)$ \\
\hline Employment & \\
\hline Housing property & \multicolumn{6}{|c|}{$\begin{array}{l}\text { No significant effect shown, see Table S3 for details } \\
\text { No significant effect shown, see Table S3 for details }\end{array}$} \\
\hline \multicolumn{7}{|c|}{ Pedestrian travel preference (Ref: Very like) } \\
\hline Very dislike & 0.445 & $0.624(0.186,2.092)$ & 0.977 & $1.018(0.306,3.383)$ & 0.489 & $0.689(0.347,1.784)$ \\
\hline Relatively dislike & 0.190 & $0.619(0.302,1.269)$ & 0.339 & $0.657(0.278,1.554)$ & 0.735 & $0.810(0.240,2.737)$ \\
\hline Normal & 0.035 & $0.591(0.362,0.964)$ & 0.146 & $0.604(0.307,1.192)$ & 0.511 & $0.771(0.355,1.676)$ \\
\hline Relatively like & 0.175 & $0.708(0.430,1.166)$ & 0.294 & $0.698(0.357,1.365)$ & 0.986 & $0.992(0.405,2.430)$ \\
\hline Age & 0.019 & $1.024(1.004,1.044)$ & 0.009 & $1.030(1.007,1.054)$ & 0.002 & $1.063(1.023,1.105)$ \\
\hline House value & 0.863 & $1.000(1.000,1.000)$ & 0.534 & $1.000(1.000,1.000)$ & 0.209 & $1.000(1.000,1.000)$ \\
\hline Number of cars & 0.341 & $0.864(0.640,1.167)$ & 0.546 & $0.896(0.629,1.278)$ & 0.718 & $0.891(0.478,1.664)$ \\
\hline $\begin{array}{l}\text { Number of electric vehicles } \\
\text { /mopeds / motorcycles }\end{array}$ & 0.448 & $0.915(0.728,1.151)$ & 0.577 & $0.929(0.717,1.204)$ & 0.670 & $0.906(0.576,1.426)$ \\
\hline Number of bicycles & 0.245 & $1.158(0.904,1.483)$ & 0.174 & $1.198(0.923,1.555)$ & 0.261 & $1.304(0.821,2.070)$ \\
\hline $\begin{array}{l}\text { Exercise frequency per } \\
\text { week }\end{array}$ & 0.168 & $1.036(0.985,1.090)$ & 0.338 & $1.198(0.923,1.555)$ & 0.399 & $1.047(0.941,1.166)$ \\
\hline Income & 0.489 & $0.980(0.934,1.002)$ & 0.952 & $0.965(0.946,1.069)$ & 0.008 & $0.968(0.947,0.974)$ \\
\hline
\end{tabular}

Dependent variable: Obesity index; Bold text indicates statistical significance $(p<0.05)$.

Taking the individual characteristics into account, in the total and the female samples, residents who are unmarried have a lower likelihood of obesity $(9.1 \%$ risk of obesity in total sample and $2.2 \%$ risk in the female sample) than those who are widowed. Similarly, with the increase of age, both men and women have an increased risk of obesity, which shows that for every one-year increase in age, men are 1.030 times more likely to be overweight or obese, while women are 1.063 times the original. Lower income is also one of the risk factors for women's obesity, which is represented in the probability of female obesity being $96.8 \%$ when the income increases by one unit. 


\subsection{Sensitivity Analysis}

After incorporating "exercise frequency per week" and "vehicle volume" into the sensitivity analysis, we have found that in the total sample and the male sample, all walking environment indicators show no significant differences (i.e., from significant to insignificant, or from insignificant to significant). However, in terms of female sample, after excluding the two indicators mentioned before, the RVI index also changes from significant to insignificant (Figure 5).

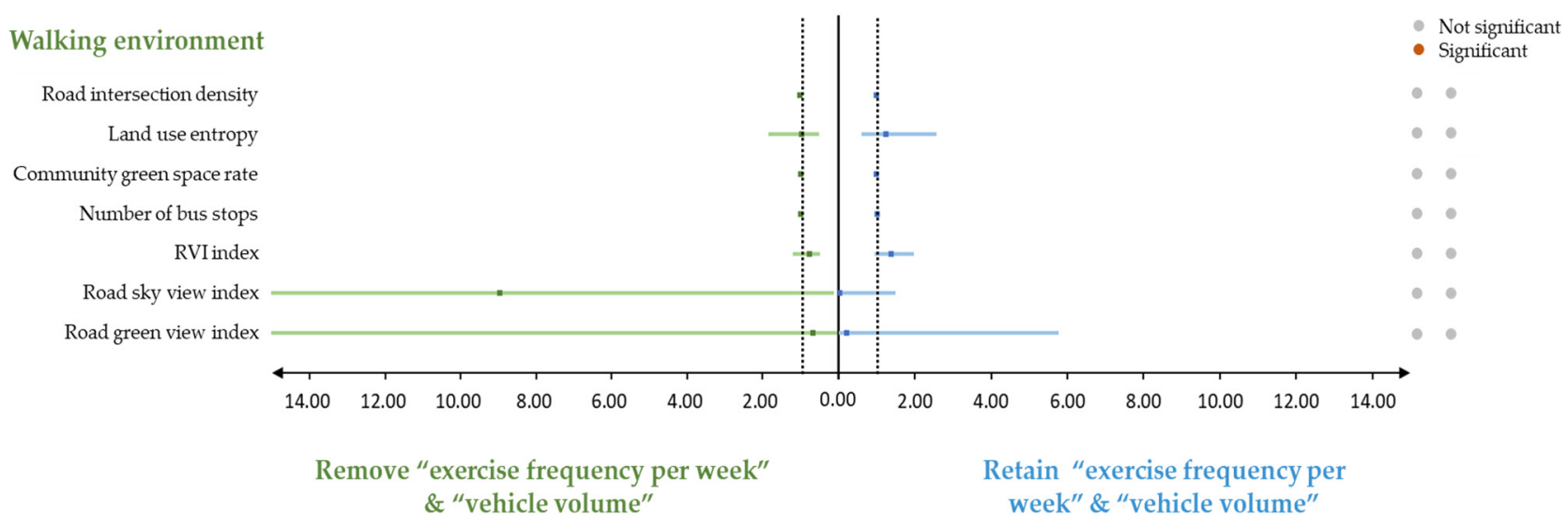

(a)

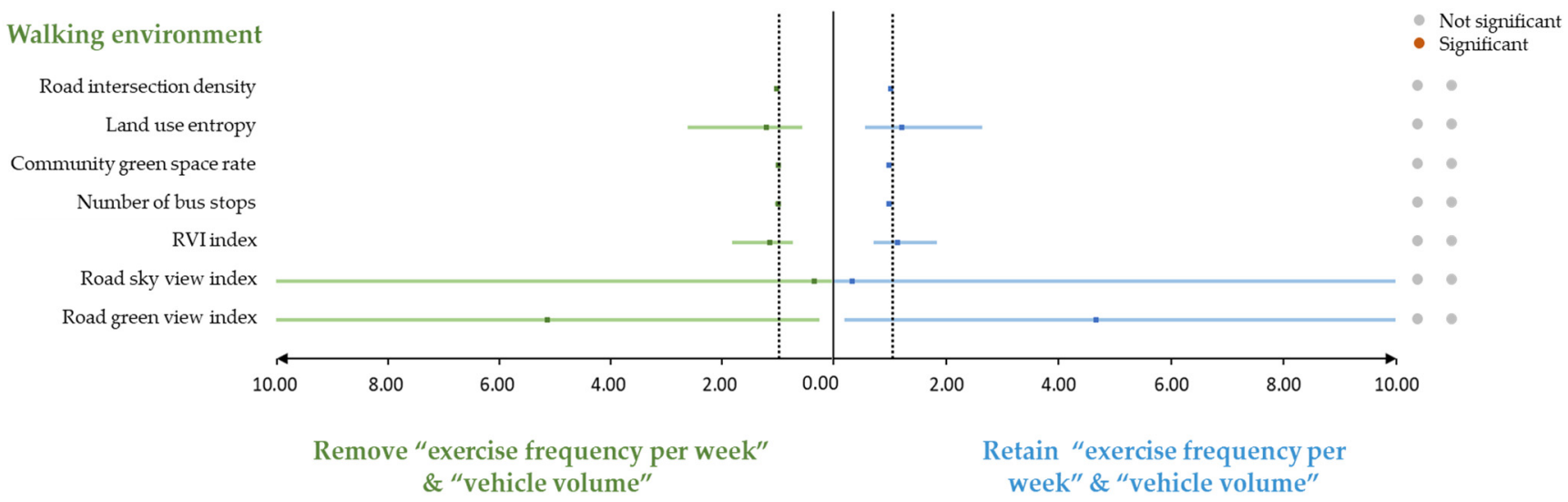

(b)

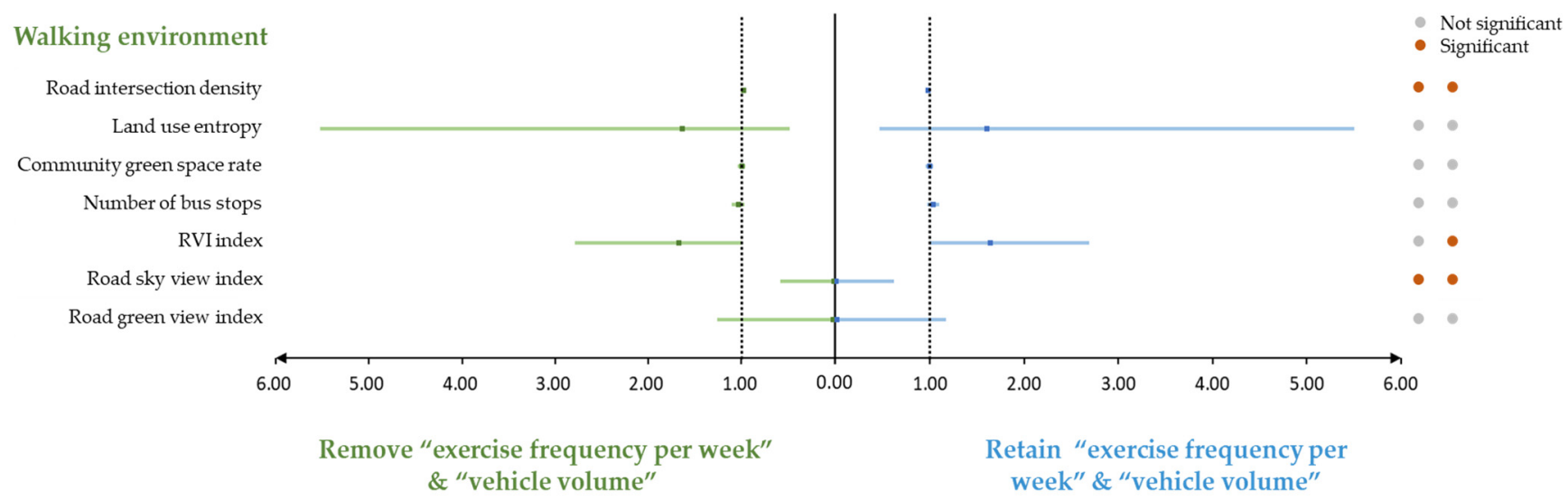

(c)

Figure 5. Sensitivity analysis. (a) Sensitivity analysis of the total sample; (b) Sensitivity analysis of the male sample; (c) Sensitivity analysis of the female sample. 


\section{Discussion}

Our research has achieved different results from previous studies and our conjecture as for the walking environment. Previous studies reported that male residents tend to use open spaces more frequently than women and are exposed to walking environments for longer periods of time; as such, a suitable walking environment could better promote men's lifestyle of physical exercise [43] and reduce the incidence of obesity. Moreover, the relationship between men and neighborhood walking environment is more consistent with the negative correlation of BMI than women $[44,45]$.

Our research, in contrast, shows that it is women who are more sensitive to the walking environment. First, one possible reason for the opposite result is that fewer Chinese women have driver's licenses than men. In the data released in 2017, the number of men holding driver's licenses accounted for $71.21 \%$ of the total number of drivers, which was significantly higher than that of women. The results also show that men's income level is generally higher (Table 1), and they have better economic ability to support a car. Even if men and women in a family hold driver's licenses, men tend to use cars more frequently than women.

Second, environmental factors related to neighborhood walking ability may also be risk factors for obesity [46]. For example, walkability has been linked to higher levels of air pollution and traffic noise exposure due to traffic congestions and greater concentration of vehicle traffic [47], which may increase the risk of obesity [48-50]. Therefore, given that men tend to use more urban space than women, their negative impact on obesity caused by exposure to air pollution, traffic noise, and other risk factors is offset by the positive impact of more walking and physical activity on reducing obesity risk. Thus, the final result is shown as insignificant, which was also confirmed in a recent study in London [51]. Therefore, a strategy to promote health along one path may have an adverse effect on another. The interactions between them should be understood to formulate more effective health promotion strategies and avoid unexpected adverse health consequences.

Third, compared with men, women pay more attention to the comfort and spaciousness of walking spaces. Women often look forward to having a safe and enjoyable experience in the outdoor environment and seek social resources and/or space for rehabilitation [52], especially for women who have formed their families. They regard walking activities during leisure time as restorative "self-time" [53] and have higher sensitivity to the blue and green spaces used during walking. Finally, this finding can also be attributed to the analysis sample. The average age of the female sample in this study is higher than that of the male sample, so the influence of age on the risk of obesity between men and women should also be considered.

In addition, female residents are more sensitive to physical activity and vehicle volume than males. After adding "exercise frequency per week" and "vehicle volume" to the model, the originally insignificant number of RVI index become significant. From a physiological point of view, obesity plays an important role in female reproduction, which is not so important for men. Therefore, women's basal metabolic rate is lower, which means that they burn less calories at rest and need more physical activity to balance. Moreover, driving behavior is a sedentary behavior that is undertaken outside the home [54], and is a determinant of weight status and poor health [55]. Consequently, controlling the impact of physical activity and vehicle volume is more important in female samples.

This study also has three limitations. First, the walking environment may change with the seasons, and the effect of plants' autumn colors, fallen leaves, and bare branches may be completely different from that of the lush period in summer. Second, our study is only a cross-sectional sample, and the scale of obesity cases is not large. Studies using larger samples, longer follow-up periods, and more accurate measurements of the community environment are needed to further elucidate the effects of walking environments on the risk of obesity among residents. In particular, isolating interpersonal relationships from socioeconomic effects to improve our understanding of the mechanisms of obesity in men and women should be the focus in future research. Third, smoking is also one of the 
important risk factors affecting obesity, but our study did not take it into account. However, the level of education has a significant impact on whether an individual smokes or not and incorporating it into the model can slightly alleviate the effects of smoking.

\section{Conclusions}

The present study included gender differences in the mechanism of the built environment's impact on obesity, revealing the relationships between built environments and residents' BMI and obesity risk using the questionnaire data of the "Daily Activities and Travel Survey of Shanghai Residents" in 54 communities in Shanghai. It suggests that: (1) women are more susceptible to the obesogenic factors than men in the aspect of the walking environment; (2) improving the topology of roads around the community and ameliorating the comfort of walking spaces have a significant impact on reducing the risk of female weight gain; and (3) improving the accessibility of bus stops will decrease women's risk of obesity.

The contribution of this study is to increase the empirical analysis that the association between the residential walking environment and change in obesity might be dependent on gender, and to demonstrate that different genders have different sensitivity levels to various indicators of walking environment. This study is the first to put forward the distinct effects of gender differences in the walking environment on residents' perception experience and behavioral choices. The theoretical framework of the walking environment that affects obesity prevalence has been improved, providing a theoretical reference for policy makers.

The policy implications of this article are that ameliorating the walkability of streets may be important public health interventions to reduce the obesity prevalence of the Shanghai population in the future (especially the female population). A large skeleton of walkable roads blocked the continuity between various functional activities of the city, which was related to the reduction in physical activities [56]. For female residents, completely separating work and residence is difficult. The working space of female residents is not only the employment space, but also the living space. Therefore, female residents need more community environments with a rich road network. In addition, the road landscape should be perfected, and the comfort of the walking environment should be enhanced. In conclusion, improving the density of road intersections, emphasizing the construction of neighborhood and community facade landscape, and stimulating the vitality of urban space are important to increase the livability of the city and ultimately affect the health and well-being of residents.

Supplementary Materials: The following supporting information can be downloaded at: https:/ / www.mdpi.com/article/10.3390/ijerph19042056/s1. Table S1: Selection of indicators for measuring the walking environment. Table S2: Generalized linear estimation equations for testing the increased BMI among residents (Connected to Table 2). Table S3: Generalized linear estimation equations for testing the risk of obesity among residents (Connected to Table 3).

Author Contributions: H.G. designed the study; Z.X. compiled the data, performed analyses, and drafted the article. Y.C. and Y.L. participated in the discussion and interpretation of findings; J.L. critically revised the manuscript for important intellectual content, approved the final version, and agreed to be accountable for all aspects of the work. All authors have read and agreed to the published version of the manuscript.

Funding: This work was supported by the Natural Science Fund of Zhejiang Province (LY22E080013), and Centre for Balance Architecture, Zhejiang University (2021-KYY-669000-0014).

Institutional Review Board Statement: Ethical review and approval were waived for this study, since we only asked participants about their height and weight.

Informed Consent Statement: Informed consent was obtained from all subjects involved in the study. For that purpose every subject that received access to the questionnaire was informed in the first page, before proceeding, with the data collection, analyses, and the publishing of results. 


\begin{abstract}
Data Availability Statement: The "Daily Activities and Travel Survey of Shanghai Residents" questionnaire data are not publicly available due to protection of privacy of the participants by all means. The Shanghai Road Network dataset was obtained from 2017 Gaode Map (https:/ /www.amap.com) (accessed on 7 July 2021). POI data was obtained from 2017 Baidu map (https://map.baidu.com) (accessed on 7 July 2021). For remote sensing image data of Shanghai, the LANDSAT 7 ETM+ (15 m) image of Shanghai in August 2017 was collected for free from the U.S. Geological Survey (https: / / www.usgs.gov /) (accessed on 7 July 2021) in the United States. The Shanghai Street View Dataset was obtained from 2017 Baidu map (https: / / map.baidu.com) (accessed on 7 July 2021).
\end{abstract}

Conflicts of Interest: The authors declare no conflict of interest.

\title{
References
}

1. Butland, B. Tackling Obesities: Future Choices-Project Report; Department of Innovation, Universities and Skills: London, UK, 2007.

2. Apovian, C.M. Participating Faculty: The Clinical and Economic Consequences of Obesity. Am. J. Manag. Care 2013, 19 (Suppl. S11), s219-s228.

3. Duncan, M.; Griffith, M.; Rutter, H.; Goldacre, M.J. Certification of obesity as a cause of death in England 1979-2006. Eur. J. Public Health 2010, 20, 671-675. [CrossRef] [PubMed]

4. Prospective Studies Collaboration. Body-mass index and cause-specific mortality in 900000 adults: Collaborative analyses of 57 prospective studies. Lancet 2009, 373, 1083-1096. [CrossRef]

5. Green, M.A. Do We Need to Think beyond BMI for Estimating Population-Level Health Risks? J. Public Health 2016, 38 , 192-193. [CrossRef]

6. Calle, E.E.; Rodriguez, C.; Walker-Thurmond, K.; Thun, M.J. Overweight, Obesity, and Mortality from Cancer in a Prospectively Studied Cohort of US Adults. N. Engl. J. Med. 2003, 348, 1625-1638. [CrossRef] [PubMed]

7. Haslam, D.W.; James, W.P.T. Obesity. Lancet 2005, 366, 1197-1209. [CrossRef]

8. Lu, Y.; Hajifathalian, K.; Ezzati, M.; Woodward, M.; Rimm, E.B.; Danaei, G. Metabolic Mediators of the Effects of Body-Mass Index, Overweight, and Obesity on Coronary Heart Disease and Stroke: A Pooled Analysis of 97 Prospective Cohorts with 1.8 Million Participants. Lancet Lond. Engl. 2013, 383, 970-983.

9. Bronfenbrenner, U.; Ceci, S.J. Nature-nuture reconceptualized in developmental perspective: A bioecological model. Psychol. Rev. 1994, 101, 568-586. [CrossRef]

10. Monteiro, C.A.; Conde, W.L.; Popkin, B.M. Independent Effects of Income and Education on the Risk of Obesity in the Brazilian Adult Population. J. Nutr. 2001, 131, 881S-886S. [CrossRef]

11. Ortiz-Moncada, R.; Garcia, M.; González-Zapata, L.I.; Fernández, E.; Álvarez-Dardet, C. Incidence of overweight and obesity in a Mediterranean population-based cohort: The Cornellà Health Interview Survey Follow-up Study (CHIS.FU). Prev. Med. 2010, 50, 45-49. [CrossRef]

12. Hosseinpour-Niazi, S.; Mirmiran, P.; Hosseinpanah, F.; Fallah-Ghohroudy, A.; Azizi, F. Association of Marital Status and Marital Transition WithMetabolic Syndrome: Tehran Lipid and Glucose Study. Int. J. Endocrinol. Metab. 2014, 12. [CrossRef]

13. Ferdinand, A.O.; Sen, B.; Rahurkar, S.; Engler, S.; Menachemi, N. The Relationship between Built Environments and Physical Activity: A Systematic Review. Am. J. Public Health 2012, 102, e7-e13. [CrossRef]

14. Durand, C.P.; Andalib, M.; Dunton, G.F.; Wolch, J.; Pentz, M.A. A systematic review of built environment factors related to physical activity and obesity risk: Implications for smart growth urban planning. Obes. Rev. 2011, 12, e173-e182. [CrossRef] [PubMed]

15. Swinburn, B.A.; Sacks, G.; Hall, K.D.; McPherson, K.; Finegood, D.T.; Moodie, M.L.; Gortmaker, S.L. The global obesity pandemic: Shaped by global drivers and local environments. Lancet 2011, 378, 804-814. [CrossRef]

16. Derose, K.P.; Han, B.; Williamson, S.; Cohen, D.A. Gender Disparities in Park Use and Physical Activity among Residents of High-Poverty Neighborhoods in Los Angeles. Women's Health Issues 2018, 28, 6-13. [CrossRef] [PubMed]

17. Dalton, R.J. Citizenship Norms and the Expansion of Political Participation. Politi. Stud. 2008, 56, 76-98. [CrossRef]

18. Jacobs, J. The Death and Life of Great American Cities; Vintage: London, UK, 2016.

19. Adkins, A.; Makarewicz, C.; Scanze, M.; Ingram, M.; Luhr, G. Contextualizing Walkability: Do Relationships between Built Environments and Walking Vary by Socioeconomic Context? J. Am. Plann. Assoc. 2017, 83, 296-314. [CrossRef] [PubMed]

20. Stafford, L.; Baldwin, C. Planning Walkable Neighborhoods: Are We Overlooking Diversity in Abilities and Ages? J. Plan. Lit. 2018, 33, 17-30. [CrossRef]

21. Valentine, G. The Geography of Women's Fear. Area 1989, 21, 385-390.

22. Pain, R.H. Social Geographies of Women's Fear of Crime. Trans. Inst. Br. Geogr. 1997, 22, 231-244.

23. Gallego, A. Unequal Political Participation in Europe. Int. J. Sociol. 2007, 37, 10-25. [CrossRef]

24. Paxton, P.; Kunovich, S.; Hughes, M.M. Gender in Politics. Annu. Rev. Sociol. 2007, 33, 263-284. [CrossRef]

25. Gardner, K.; Johnson, T.; Buchan, K.; Pharaoh, T. Developing a Pedestrian Strategy for London. Transport Policy and Its Implementation. Proceedings of Seminar B Held at the 24th European Transport Forum, Brunel University Henley-in-Arden, London, UK, 2-6 September 1996; p. 402. 
26. Moura, F.; Cambra, P.; Gonçalves, A.B. Measuring walkability for distinct pedestrian groups with a participatory assessment method: A case study in Lisbon. Landsc. Urban Plan. 2017, 157, 282-296. [CrossRef]

27. Cervero, R.; Kockelman, K. Travel demand and the 3Ds: Density, diversity, and design. Transp. Res. Part D Transp. Environ. 1997, 2, 199-219. [CrossRef]

28. Ewing, R.; Connors, M.B.; Goates, J.P.; Hajrasouliha, A.; Neckerman, K.; Nelson, A.C.; Greene, W. Validating Urban Design Measures. In Transportation Research Board Meeting. Transportation Research Board Meeting, Washington, DC, USA, 13-17 January 2013; Available online: http:/ / trid.trb.org/view.aspx?id=1241107 (accessed on 7 July 2021).

29. Pikora, T.J.; Giles-Corti, B.; Knuiman, M.W.; Bull, F.C.; Jamrozik, K.; Donovan, R.J. Neighborhood Environmental Factors Correlated with Walking near Home: Using SPACES. Med. Sci. Sports Exerc. 2006, 38, 708-714. [CrossRef] [PubMed]

30. Day, K.; Boarnet, M.; Alfonzo, M.; Forsyth, A. The Irvine-Minnesota Inventory to Measure Built Environments: Development. Am. J. Prev. Med. 2006, 30, 144-152. [CrossRef]

31. Clifton, K.; Livi, A.; Rodriguez, D.A. Pedestrian Environment Data Scan (PEDS) Tool. Planning 2005, 80, 95-110.

32. Kelly, C.; Tight, M.; Hodgson, F.; Page, M. A comparison of three methods for assessing the walkability of the pedestrian environment. J. Transp. Geogr. 2011, 19, 1500-1508. [CrossRef]

33. Berrigan, D.; Pickle, L.W.; Dill, J. Associations between street connectivity and active transportation. Int. J. Health Geogr. 2010, 9 , 1-18. [CrossRef]

34. Tal, G.; Handy, S. Measuring Nonmotorized Accessibility and Connectivity in a Robust Pedestrian Network. Transp. Res. Rec. 2012, 2299, 48-56. [CrossRef]

35. Cervero, R.; Sarmiento, O.L.; Jacoby, E.; Gomez, L.F.; Neiman, A. Influences of Built Environments on Walking and Cycling: Lessons from Bogotá. Int. J. Sustain. Transp. 2009, 3, 203-226. [CrossRef]

36. Frank, L.D.; Schmid, T.L.; Sallis, J.F.; Chapman, J.; Saelens, B.E. Linking objectively measured physical activity with objectively measured urban form: Findings from SMARTRAQ. Am. J. Prev. Med. 2005, 28, 117-125. [CrossRef] [PubMed]

37. Loo, B.P.Y.; Lam, W.W.Y.; Mahendran, R.; Katagiri, K. How Is the Neighborhood Environment Related to the Health of Seniors Living in Hong Kong, Singapore, and Tokyo? Some Insights for Promoting Aging in Place. Ann. Am. Assoc. Geogr. 2017, 107, 812-828. [CrossRef]

38. Dai, D. Identifying clusters and risk factors of injuries in pedestrian-vehicle crashes in a GIS environment. J. Transp. Geogr. 2012, 24, 206-214. [CrossRef]

39. Kimpton, A.; Corcoran, J.; Wickes, R. Greenspace and Crime: An Analysis of Greenspace Types, Neighboring Composition, and the Temporal Dimensions of Crime. J. Res. Crime Delinq. 2017, 54, 303-337. [CrossRef]

40. Sreetheran, M.; Van Den Bosch, C.C.K. A Socio-Ecological Exploration of Fear of Crime in Urban Green Spaces-A Systematic Review. Urban For. Urban Green. 2014, 13, 1-18. [CrossRef]

41. Crawford, D.; Timperio, A.; Giles-Corti, B.; Ball, K.; Hume, C.; Roberts, R.; Andrianopoulos, N.; Salmon, J. Do Features of Public Open Spaces Vary According to Neighbourhood Socio-Economic Status? Health Place 2008, 14, 889-893. [CrossRef]

42. Jones, A.; Hillsdon, M.; Coombes, E. Greenspace access, use, and physical activity: Understanding the effects of area deprivation. Prev. Med. 2009, 49, 500-505. [CrossRef]

43. Sundquist, K.; Eriksson, U.; Kawakami, N.; Skog, L.; Ohlsson, H.; Arvidsson, D. Neighborhood walkability, physical activity, and walking behavior: The Swedish Neighborhood and Physical Activity (SNAP) study. Soc. Sci. Med. 2011, 72, 1266-1273. [CrossRef]

44. Frank, L.D.; Andresen, M.A.; Schmid, T.L. Obesity relationships with community design, physical activity, and time spent in cars. Am. J. Prev. Med. 2004, 27, 87-96. [CrossRef]

45. Frank, L.D.; Kerr, J.; Sallis, J.F.; Miles, R.; Chapman, J. A hierarchy of sociodemographic and environmental correlates of walking and obesity. Prev. Med. 2008, 47, 172-178. [CrossRef] [PubMed]

46. Frank, L.D.; Iroz-Elardo, N.; MacLeod, K.E.; Hong, A. Pathways from built environment to health: A conceptual framework linking behavior and exposure-based impacts. J. Transp. Health 2019, 12, 319-335. [CrossRef]

47. Marshall, J.D.; Brauer, M.; Frank, L.D. Healthy Neighborhoods: Walkability and Air Pollution. Environ. Health Perspect. 2009, 117, 1752-1759. [CrossRef]

48. Liu, X.; Tu, R.; Qiao, D.; Niu, M.; Li, R.; Mao, Z.; Huo, W.; Chen, G.; Xiang, H.; Guo, Y.; et al. Association between long-term exposure to ambient air pollution and obesity in a Chinese rural population: The Henan Rural Cohort Study. Environ. Pollut. 2020, 260, 114077. [CrossRef]

49. Furlong, M.A.; Klimentidis, Y.C. Associations of air pollution with obesity and body fat percentage, and modification by polygenic risk score for BMI in the UK Biobank. Environ. Res. 2020, 185, 109364. [CrossRef]

50. Oftedal, B.; Krog, N.H.; Pyko, A.; Eriksson, C.; Graff-Iversen, S.; Haugen, M.; Schwarze, P.; Pershagen, G.; Aasvang, G.M. Road Traffic Noise and Markers of Obesity-A Population-Based Study. Environ. Res. 2015, 138, 144-153. [CrossRef]

51. Sinharay, R.; Gong, J.; Barratt, B.; Ohman-Strickland, P.; Ernst, S.; Kelly, F.J.; Zhang, J.; Collins, P.; Cullinan, P.; Chung, K.F. Respiratory and cardiovascular responses to walking down a traffic-polluted road compared with walking in a traffic-free area in participants aged 60 years and older with chronic lung or heart disease and age-matched healthy controls: A randomised, crossover study. Lancet 2018, 391, 339-349. [CrossRef]

52. Morris, S.; Guell, C.; Pollard, T.M. Group Walking as a "Lifeline": Understanding the Place of Outdoor Walking Groups in Women's Lives. Soc. Sci. Med. 2019, 238, 112489. [CrossRef] [PubMed] 
53. Lloyd, K.; O'Brien, W.; Riot, C. Mothers with young children: Caring for the self through the physical activity space. Leis. Sci. 2016, 38, 85-99. [CrossRef]

54. McCormack, G.R.; Virk, J.S. Driving towards obesity: A systematized literature review on the association between motor vehicle travel time and distance and weight status in adults. Prev. Med. 2014, 66, 49-55. [CrossRef]

55. Owen, N.; Healy, G.N.; Matthews, C.E.; Dunstan, D.W. Too Much Sitting: The Population-Health Science of Sedentary Behavior. Exerc. Sport Sci. Rev. 2010, 38, 105. [CrossRef] [PubMed]

56. Frank, L.D.; Sallis, J.F.; Conway, T.L.; Chapman, J.E.; Saelens, B.E.; Bachman, W. Many Pathways from Land Use to Health: Associations between Neighborhood Walkability and Active Transportation, Body Mass Index, and Air Quality. J. Am. Plan. Assoc. 2006, 72, 75-87. [CrossRef] 